\title{
Karakteristik Reologi Komposit Serbuk Cangkang Kemiri dan Poliuretan
}

\author{
Yovial Mahyoedin ${ }^{1}$, Kurnia Harlina Dewi ${ }^{2}$, Wenny Marthiana ${ }^{1}$, Rizky Arman ${ }^{1}$. Ridho Azhari ${ }^{1}$ \\ ${ }^{1}$ Jurusan Teknik Mesin - Fakultas Teknologi Industri, Universitas Bung Hatta, Padang \\ ${ }^{2}$ Jurusan Teknologi Industri Pertanian - Fakultas Pertanian, Universitas Bengkulu, Bengkulu \\ correspondent author: jmahyoedin@yahoo.com
}

\begin{abstract}
Abstrak
Penelitian ini bertujuan menentukan karakteristik reologi komposit serbuk cangkang kemiri (SCK) berukuran $45 \mu m<d<75 \mu m$ dan resin Poliuretan (PU) dengan komposisi bervariasi, yaitu 5\%:95\%, 10\%:90\%, 15\%:85\%. Pencampuran SCK dan PU dilakukan dengan mechanical mixer dengan kecepatan dan lama pengadukan masing-masing 10, 15 dan 20 menit dan 100, 200 dan 250 rpm. Reologi komposit diperoleh dengan pengujian rotational viscometer dan dioptimasi dengan metoda Taguchi. Penelitian menunjukkan viskositas terkecil 218,66 mPa.s, ditemukan pada komposit dengan komposisi 5\% 95\%, waktu pengadukan 15 menit dan kecepatan pengadukan $100 \mathrm{rpm}$.
\end{abstract}

Kata kunci: Serbuk cangkang kemiri, Poliuretan, Viskositas, Reologi.

\begin{abstract}
This study aimed to determine the composite rheological characteristics of candlenut shells (SCK) with particle size of $45 \mu \mathrm{m}<d<75 \mu \mathrm{m}$ and polyurethane $(P U)$ resins with varying compositions, namely 5\%: 95\%, 10\%: 90\%, 15\%: 85\%. Mixing of SCK and PU is carried out using mechanical mixers with a speed and stirring time of 10, 15 and 20 minutes and 100, 200 and 250 rpm, respectively. Composite rheology was obtained by rotational viscometer testing and optimized by the Taguchi method. The results showed the smallest viscosity of 218.66 mPa.s, found in composites with a composition of 5\% 95\%, stirring time of 15 minutes and stirring speed of 100 rpm.
\end{abstract}

Keywords: candlenut shell, polyurethane, viscosity, rheology

\section{Pendahuluan}

Kemiri (Aleurites moluccana Wild) merupakan salah satu komoditas Hasil Hutan Non Kayu (HHNK) penting yang dapat tumbuh subur pada tanah berpasir dan bahkan tanah yang kurang subur sekalipun. Tempurung biji kemiri memiliki sifat keras, cukup tebal dan berkayu, dan umumnya (60-70\%) merupakan limbah. Pemanfaatan limbah padat kemiri dalam bidang teknologi bahan belum begitu banyak dilakukan khususnya penelitian mengenai pemanfaatan limbah padat kemiri sebagai material penguat komposit. Menurut Dinas Perkebunan Sumatera Barat, pada tahun 2014 produksi kemiri sebesar 9200 ton dengan potensi limbah mencapai 6899,9 ton [1].

Poliuretan (Polyurethane) memiliki banyak kegunaan, diantaranya sekitar 70\% digunakan sebagai busa (foam), selebihnya sebagai bahan elastomer, lem dan pelapis (coating) [2,3]. Kelompok resin ini menghasilkan sifat pengeringan fisik yang sangat baik dalam bahan pelapis, memiliki sifat wetting pigmen yang sangat baik [4], menunjukkan ketahanan yang lebih baik terhadap bahan kimia daripada poliester, dan memberikan pelapisan dengan sifat mekanik yang sangat luas karena mereka dapat menghasilkan substruktur dengan cara pembentukan fase $[5,6]$. Poliuretan juga menarik dari sudut pandang pengaturan sifat reologi dari bahan pelapis.

Viskositas, resistensi terhadap aliran, adalah karakteristik reologi yang paling penting dari cairan bahan coating. Bahkan lebih penting adalah perubahan viskositas selama coating. 
Fluida Newtonian, seperti pelarut, memiliki viskositas mutlak yang tidak berubah dengan penerapan geser mekanis. Namun, hampir semua coating menunjukkan perubahan yang signifikan dalam viskositas jika diterapkan gaya yang berbeda. Viskositas sederhananya adalah rasio tegangan geser dengan laju geser. Fluida dengan viskositas tinggi membutuhkan gaya (kerja) yang besar untuk menghasilkan perubahan bentuk. Coating dengan viskositas tinggi, selain sukar, juga memerlukan waktu lebih lama untuk mengalir keluar bila digunakan. [7]

Menurut Kendal (2001) [8] partikel serbuk berada pada keseimbangan gravitasi dan gaya inter-partikel. Semakin kecil ukuran partikel, gravitasi partikel menjadi kurang signifikan sehingga gaya inter-partikel akan makin dominan. Karena itu, penggunaan serbuk yang lebih halus akan lebih sukar. Oleh karena itu, penggunaan serbuk halus pada powder coating lebih sulit daripada serbuk dengan ukuran biasa. Penelitian ini dilakukan untuk mengetahui karakteristik reologi dari komposit serbuk cangkang kemiri dengan poliuretan sebagai alternatif bahan coating.

\section{Metodologi Penelitian}

Bahan yang digunakan pada penelitian ini adalah serbuk cangkang kemiri (SCK) dengan ukuran serbuk $45<\mathrm{D}<75 \mu \mathrm{m}$ dan resin poliuretan+hardener yang disuplai dari PT. Brataco. Densitas masing-masing bahan telah diukur terlebih dahulu (Tabel 2.1). Preparasi dilakukan dalam beberapa tahap, yaitu proses pengolahan SCK dan pencampuran SCK dan Poliuretan (PU). SCK dihancurkan dengan crusher hingga menjadi serbuk, kemudian disortir dengan peralatan sieve shaker untuk memperoleh ukuran serbuk yang dikehendaki, lalu dikeringkan.

Tabel 2.1. Densitas Bahan

\begin{tabular}{|l|c|}
\hline \multicolumn{1}{|c|}{ Material } & Densitas $\rho\left(\mathrm{gr} / \mathrm{cm}^{3}\right)$ \\
\hline Poliuretan & 1,220 \\
Serbuk Cangkang Kemiri & 1,143 \\
\hline
\end{tabular}

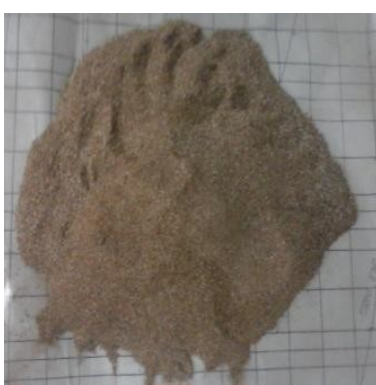

Gambar 2.1

Serbuk Cangkang Kemiri

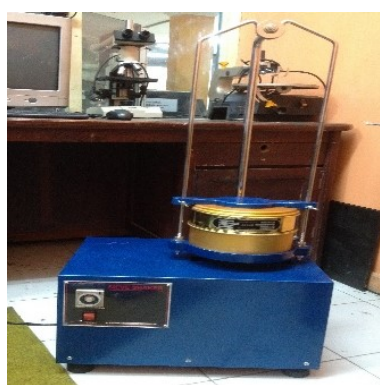

Gambar 2.2.

Sieve Shaker

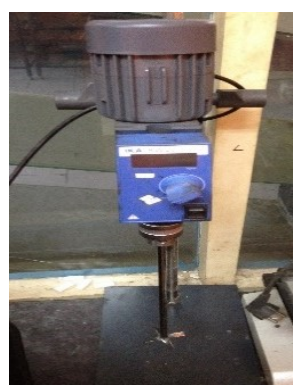

Gambar2.3.

Mechanical Mixer

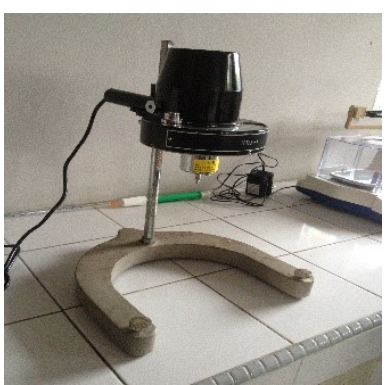

Gambar2.4.

Rotasional viskometer

SCK dan PU dicampur dengan komposisi tertentu (\% wt), yaitu 5\%:95\%, 10\%:90\%, 15\%:85\%. Pencampuran menggunakan mechanical mixer dengan kecepatan dan waktu pengadukan masing masing 10,15 dan 20 menit dan 100, 200 dan $250 \mathrm{rpm}$. Viskositas campuran kemudian diukur dengan menggunakan rotasional viscometer Brookfield (Gambar 2.1-2.4).

Pengukuran viskositas menghasilkan data absolute viscosity (mPa.s) dengan persamaan:

Dimana :

$$
\eta=\mathrm{k} . \mathrm{a}
$$




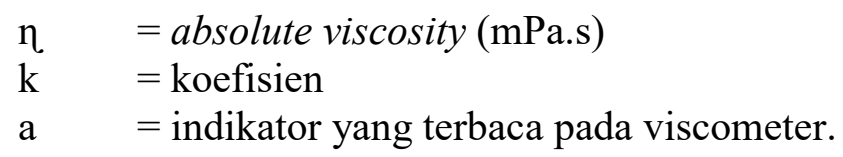

Nilai koefisien diperoleh dari tabel 2.2, dengan memilih kecepatan pengadukan $30 \mathrm{rpm}$ dan rotor yang dipakai adalah rotor nomor 2,3 , dan 4 .

Tabel 2.2 Koefisien viskometer

\begin{tabular}{|c|c|c|c|c|}
\hline $\begin{array}{c}\text { rpoefisien } \\
\text { rotor }\end{array}$ & 60 & 30 & 12 & 6 \\
\hline 1 & 1 & 2 & 5 & 10 \\
\hline 2 & 5 & 10 & 25 & 50 \\
\hline 3 & 20 & 40 & 100 & 200 \\
\hline 4 & 100 & 200 & 500 & 1000 \\
\hline
\end{tabular}

Penelitian ini meninjau faktor proses pembentukan komposit (spesimen), yaitu proses pencampuran bahan SCK dan PU. Parameter proses pembentukan komposit kemudian dioptimasi dengan metoda Taguchi, menggunakan 4 faktor dengan rancangan 3 level. Metode Taguchi adalah metode eksperimen yang bertujuan untuk memperbaiki kualitas dari suatu produk dan proses dalam waktu yang bersamaan untuk menekan biaya dan sumber daya seminimal mungkin sehingga dicapai kondisi yang optimal dan efisien [9]. Dari level dan faktor di atas maka rancangan matrik ortogonal yang digunakan adalah L9 $\left(3^{2}\right)$, yang menunjukkan jumlah percobaan sebanyak 9 run. Run ini direplikasi sebanyak 3 kali sehingga total eksperimen sejumlah 27 eksperimen dilakukan untuk setiap pengujian. Faktor dan level dapat dilihat pada tabel 2.3.

Tabel 2.3 Faktor dan level

\begin{tabular}{|l|l|c|c|c|}
\hline \multirow{2}{*}{ No } & \multicolumn{1}{|c|}{ Faktor } & \multicolumn{3}{|c|}{ Level } \\
\cline { 3 - 5 } & & 1 & 2 & 3 \\
\hline 1 & Jumlah SCK (\% wt) & $5 \%$ & $10 \%$ & $15 \%$ \\
2 & Kec. mixing (rpm) & 100 & 200 & 250 \\
3 & Waktu mixing (menit) & 10 & 15 & 20 \\
4 & Hardener (ml) & 5 & 10 & 15 \\
\hline
\end{tabular}

Data yang diambil dari percobaan adalah data viskositas yang diberikan oleh peralatan rotasional viscometer. Perhitungan $\mathrm{S} / \mathrm{N}$ ratio dilakukan dengan menggunakan program Minitab. S/N ratio adalah logaritma dari suatu fungsi kerugian kuadratik dan digunakan untuk mengevaluasi kualitas produk bahan komposit yang dihasilkan dari pencampuran SCK dan PU. Dalam penelitian ini digunakan $\mathrm{S} / \mathrm{N}$ ratio jenis smaller is better karena jenis karakteristik mutu viskositas untuk bahan powder coating adalah makin kecil makin baik.

\section{Hasil dan Pembahasan}

Berdasarkan pengujian yang dilakukan terhadap seluruh spesimen, diperoleh data viskositas yang selanjutnya dianalisis sesuai dengan prosedur yang telah ditetapkan pada bagian metodologi penelitian sehingga diperoleh hasil pengujian seperti ditunjukkan pada tabel 3.1.

Tabel 3.1. Data viskositas campuran SCK dan PU

\begin{tabular}{cllll}
\hline run & rata-rata $\eta(\mathrm{mPa} . \mathrm{s})$ & & Run & rata-rata $\eta(\mathrm{mPa} . \mathrm{s})$ \\
\cline { 1 - 1 } \cline { 5 - 6 } & 258 & & 6. & 321,33 \\
\hline
\end{tabular}




\begin{tabular}{lllll}
\hline 2. & 253,66 & & 7. & 490,66 \\
\cline { 3 - 4 } 3. & 223,33 & & 8. & 460,33 \\
4. & 260 & & 9. & 510 \\
5. & 384,33 & & \\
\cline { 3 - 5 }
\end{tabular}

Analisa respon nilai tabel dan grafik untuk $\boldsymbol{S} / \boldsymbol{N}$ ratio. Untuk faktor kontrol dalam mengindifikasi pengaruh level dari faktor terhadap rata-rata viskositas campuran SCK dan PU, dilakukan pengolahan data respon (viskositas) yang diperoleh langsung dari setiap tahap percobaan. Pengaruh level dan faktor terlihat pada Tabel 5 berikut:

Tabel 3.2. Respon Signal to Noise (S/N) ratioSmaller is better

\begin{tabular}{|c|c|c|c|c|}
\hline \multirow{2}{*}{ Level } & \multicolumn{4}{|c|}{ Faktor } \\
\cline { 2 - 5 } & Komposisi & Putaran & Waktu & Hardener \\
\hline 1 & $-47,52$ & $-49,29$ & $-50,54$ & $-51,36$ \\
2 & $-50,04$ & $-51,01$ & $-49,33$ & $-50,68$ \\
3 & $-53,74$ & $-50,42$ & $-50,83$ & $-48,83$ \\
\hline Delta & 6,22 & 1,73 & 1,50 & 2,53 \\
\hline Rank & 1 & 3 & 4 & 2 \\
\hline
\end{tabular}

Berdasarkan perbandingan hasil dari analisis Taguchi baik menggunakan analysis anova for $S / N$ ratio ataupun analysis anova for mean menunjukkan bahwa hasil kedua analisis tersebut menyatakan bahwa komposisi campuran merupakan parameter yang paling berpengaruh dalam menurunkan nilai viskositas campuran. Hardener merupakan faktor kedua dalam menurunkan nilai viskositas campuran. Faktor berikutnya adalah kecepatan pengadukan dan yang terakhir waktu pengadukan. Hal tersebut ditunjukkan dalam ranking faktor pada tabel 3.2

Berdasarkan data hasil rata-rata $\mathrm{S} / \mathrm{N}$ rasio pada Tabel 3.2. didapat gambar grafik respon $\mathrm{S} / \mathrm{N}$ seperti pada Gambar 5 berikut.

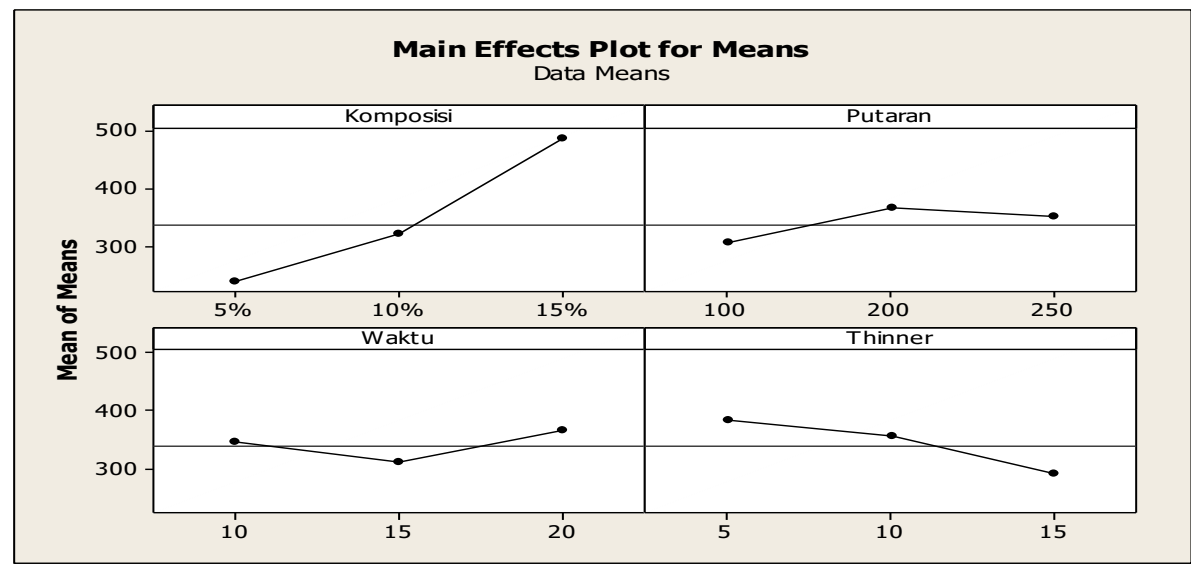

Gambar .31. Grafik S/N untuk respon nilai rata-rata viskositas campuran

Berdasarkan analisa pada Tabel 3.2 dan Gambar 3.1, parameter yang mempengaruhi viskositas campuran SCK dan PU paling kecil masing-masing adalah komposisi level 1, kecepatan putaran (pengadukan) pada level 1, waktu pengadukan pada level 2 dan hardener (thinner) pada level 3. Hal tersebut dapat dilihat pada Tabel 6 berikut:

Tabel 6. Respon parameter proses pembentukan terbaik.

\begin{tabular}{|c|c|c|}
\hline Faktor & Level & Nilai \\
\hline Jumlah SCK (\% wt) & 1 & $5 \%$ \\
\hline
\end{tabular}




\begin{tabular}{|l|c|c|}
\hline Kec. mixing (rpm) & 1 & 100 \\
Waktu mixing (menit) & 2 & 15 \\
Hardener (ml) & 3 & 15 \\
\hline
\end{tabular}

Dari data respon tersebut, seperti yang ditunjukkan pada tabel 6, dapat disimpulkan bahwa jumlah serbuk yang kecil menghasilkan viskositas campuran yang rendah. Penelitian sebelumnya menunjukkan bahwa semakin banyak jumlah filler (dalam hal ini SCK), semakin sukar campuran mengalir karena jumlah resin yang makin sedikit, yang berarti bahwa viskositas campuran akan makin besar [10].

Kecepatan putaran (pengadukan) yang rendah pula akan menghasilkan viskositas yang rendah, seperti yang ditunjukkan pada table 6 . Nampaknya pengaruh kecepatan pengadukan berkaitan dengan homogenitas campuran. Semakin rendah kecepatan pengadukan maka kedua-dua bahan berpeluang untuk bercampur dengan lebih merata (homogen). Hasil ini parallel dengan penelitian sebelumnya yang menunjukkan bahwa campuran yang lebih homogen memberikan viskositas yang makin rendah [11].

Sedangkan, waktu pengadukan nampaknya menunjukkan fenomena keseimbangan antara homogenitas dan peningkatan suhu. Seperti telah dibahas di atas, campuran yang homogen memiliki viskositas yang rendah. Sedangkan, waktu pengadukan yang lama berpeluang meningkatkan suhu campuran. Peningkatan suhu, pada gilirannya menghasilkan viskositas campuran yang rendah.

Hardener (thinner) adalah cairan kimia yang berperan sebagai katalis dalam proses pembentukan campuran. makin banyak hardener yang ditambahkan, makin cepat resin PU mengeras. Sebaliknya, makin banyak hardener yang ditambahkan, makin lama resin PU mengeras. Oleh karena itu, dapat dimengerti bahwa resin yang lebih lama mengeras berarti memiliki sifat alir yang lebih baik, yang pada gilirannya memberikan nilai viskositas yang rendah.

Dari hasil pengujian viskositas di atas yang memberikan respon parameter terbaik, maka dilakukan pengujian untuk klarifikasi sesuai parameter seperti pada tabel 6. Hasil yang diperoleh ditunjukkan pada table 7 .

Tabel 7. Nilai viskositas yang mengikuti parameter Taguchi

\begin{tabular}{|c|c|c|c|c|c|}
\hline \multirow{2}{*}{ run } & rotor & Indikator & koefisien & $\eta$ (mPa.s) & $\begin{array}{c}\text { Rata rata } \eta \\
\text { (mPa.s) }\end{array}$ \\
\hline \multirow{2}{*}{10} & \multirow{2}{*}{30} & 3,2 & 10 & 32 & \multirow{2}{*}{218,66} \\
\cline { 3 - 5 } & & 4,1 & 40 & 164 & \\
\cline { 3 - 5 } & & 2,3 & 200 & 460 & \\
\hline
\end{tabular}

\section{Kesimpulan}

Berdasarkan hasil eksperimen dan analisis yang telah dilakukan, dapat diambil kesimpulan sebagai berikut:

a. Dari kesembilan percobaan yang dilakukan, komposisi campuran merupakan parameter yang sangat berperan dalam menentukan nilai viskositas bahan campuran. Semakin rendah kandungan SCK dalam campuran, viskositas campuran akan makin kecil, dan sebaliknya.

b. Kecepatan dan waktu pengadukan merupakan faktor mekanik yang terkait dengan homogenitas campuran. Ada indikasi bahwa kedua faktor tersebut juga berhubungan dengan jumlah kandungan serbuk dalam campuran. Semakin besar kandungan SCK, waktu dan kecepatan pengadukan untuk menghasilkan campuran yang homogen mungkin berpengaruh, yang pada gilirannya mempengaruhi nilai viskositas bahan campuran. 
c. Hardener sebagai katalis dalam reaksi kimia PU berperan cukup besar dalam mempengaruhi nilai viskositas campuran. Semakin banyak hardener, viskositas campuran akan semakin rendah.

d. Verifikasi yang dilakukan menunjukkan bahwa nilai viskositas campuran yang diperoleh sangat rendah, yaitu sebesar 218,66 mPa.s, pada komposisi SCK dan PU 5\%:95\%, kecepatan pengadukan $100 \mathrm{rpm}$, waktu pengadukan 15 menit dan hardener $15 \mathrm{ml}$. Hasil yang diperoleh ini sesuai dengan perkiraan viskositas campuran untuk parameter seperti yang disarankan Taguchi.

\section{Referensi}

1. http://www.sumbarprov.go.id/details/news/6376.

2. Cheremisinoff, P. Nicholas. 1989. Handbook of Polymer Science and Technology, Vol.2.

3. Stevens, P. Malcolm P. 1998. Polymer Chemistry: An Introduction, 3rd Ed. Oxford University Press.

4. Satguru, R., Mac Mahon, I., Padget, J.C., Coogan, R.C. 1994 Journal of Coatings Technology, 66(830), 55.

5. Wang, T.-L.D., Lyman, D.J. 1993. Journal of Polymer Science Part A: Polymer Chemistry, 31, 1983.

6. Saidah, A., Susilowati, S.E. and Nofendri, Y., 2018. PENGARUH FRAKSI VOLUME SERAT TERHADAP KEKUATAN MEKANIK KOMPOSIT SERAT JERAMI PADI EPOXY DAN SERAT JERAMI PADI RESIN YUKALAC 157. Jurnal Konversi Energi dan Manufaktur UNJ, 5(2), pp.96-101.

7. Talbert. 2008. Paint Technology Handbook. Taylor \& Francis Group, LLC, Boca Raton.

8. Kendall K., Stainton C., 2001, Adhesion and aggregation of fine particles, PowderTechnol., 121, 223-229.

9. Montgomery Douglas C. 2012. Design and Analysis of Experiments. 8th Ed. Willey Publisher.

10. Mahyoedin Y., Jaafar S., Norhamidi M., Andanastuti M., Suryadimal. 2018. Effect of graphite sizes and carbon black content on flowability of the injection molded conductive. MATEC Web of Conferences vol. 248.

11. Mahyoedin Y., Jaafar S., Norhamidi M., Andanastuti M., Iqbal. 2018. Peculiarity of Injection Molding Composites. MATEC Web of Conferences vol. 248 